\title{
Article
}

\section{You'll never walk alone: supportive social relations in a football and mental health project}

Mckeown, Michael, Roy, Alastair Neil and Spandler, Helen

Available at http://clok.uclan.ac.uk/11353/

Mckeown, Michael ORCID: 0000-0003-0235-1923, Roy, Alastair Neil ORCID: 0000-0002-4807-7352 and Spandler, Helen ORCID: 0000-0002-0970-5141 (2015) You'll never walk alone: supportive social relations in a football and mental health project. International Journal Of Mental Health Nursing, 24 (4). pp. 360-369. ISSN 1445-8330

It is advisable to refer to the publisher's version if you intend to cite from the work. http://dx.doi.org/10.1111/inm.12122

For more information about UCLan's research in this area go to http://www.uclan.ac.uk/researchgroups/ and search for <name of research Group>.

For information about Research generally at UCLan please go to http://www.uclan.ac.uk/research/

All outputs in CLoK are protected by Intellectual Property Rights law, including Copyright law. Copyright, IPR and Moral Rights for the works on this site are retained by the individual authors and/or other copyright owners. Terms and conditions for use of this material are defined in the policies page.

\section{CLoK}

Central Lancashire online Knowledge www.clok.uclan.ac.uk

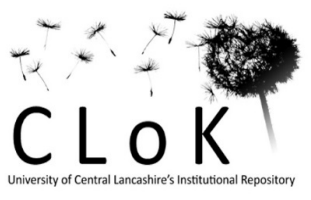




\section{You'll never walk alone:}

\section{Supportive social relations in a football and mental health project}

Accepted for publication: International Journal of Mental Health Nursing

Mick McKeown ${ }^{1} \mathrm{PhD}, \mathrm{BA}$ (hons), RGN, RMN - Reader in Democratic Mental Health, School of Health, University of Central Lancashire

Alastair Roy PhD, BA (hons), CQYW -Reader in Social Research, School of Social Work, University of Central Lancashire

Helen Spandler, PhD, MA, BA (hons) - Reader in Mental Health, School of Social Work, University of Central Lancashire

${ }^{1}$ Corresponding author details:

Mick McKeown

School of Health, University of Central Lancashire, Preston PR1 2HE

e-mail: $\underline{\text { mmckeown@uclan.ac.uk }}$

fax: 01772892998

tel: 01772893818

Short running head: You'll never walk alone 


\title{
You'll never walk alone: supportive social relations in a football and mental health project
}

\begin{abstract}
Football can bring people together in acts of solidarity and togetherness. This spirit is most evocatively illustrated in the world renowned football anthem You'll Never Walk Alone (YNWA). In this paper we argue that this spirit can be effectively harnessed in nursing and mental health care. We draw on data from qualitative interviews undertaken as part of evaluating a football and mental health project to explore the nature of supportive social relations therein. We use some of the lyrics from YNWA as metaphor to frame our thematic analysis. We are especially interested in the interactions between the group facilitators and group members, but also address aspects of peer support within the groups. A contrast is drawn between the flexible interpersonal boundaries and self-disclosure evident in the football initiative and the reported more distant relations with practitioners in mainstream mental health services. Findings suggest scope for utilising more collective, solidarity enhancing initiatives and attention to alliances and boundaries to maximise engagement and therapeutic benefits within routine practice.
\end{abstract}

Key words: therapeutic alliance, peer support, self-disclosure, mental health services, football, mental health.

Word length: 4, 993 
You'll never walk alone: supportive social relations in a football and mental health project

When you walk through a storm

Hold your head up high

And don't be afraid of the dark

Walk on through the wind

Walk on through the rain

Though your dreams be tossed and blown

Walk on, walk on with hope in your heart

And you'll never walk alone

You'll never walk alone

At the end of the storm there's a golden sky

And the sweet silver sound of the lark

Walk on, walk on with hope in your heart

And you'll never walk alone

Copyright (C) 1945 by Richard Rodgers \& Oscar Hammerstein II. Copyright Renewed. International Copyright Secured. All Rights Reserved.

Used by Permission of Williamson Music, A Division of Rodgers \& Hammerstein: An Imagem Company 


\section{Introduction}

At half-time in the 2005 European Champions League final, Istanbul, Liverpool Football Club were 3-0 down and effectively dead and buried. Rafa Benitez, the coach, is credited with a rousing speech in the dressing room that so motivated the players they achieved the impossible, overturning the three goal deficit and eventually winning the much coveted trophy. But something else happened during that half-time break. The Liverpool fans, facing the heartbreak of defeat, rallied themselves to loudly sing You'll Never Walk Alone (YNWA). Reportedly, this simple act of pride, defiance and togetherness also reached the ears of the players, having a galvanising effect on their performance (Balague 2005).

In other circumstances, large numbers of Liverpool fans gather once a year on April $15^{\text {th }}$ at the Anfield football stadium to remember the 96 fans who perished in the infamous Hillsborough disaster of 1989. YNWA is sung respectfully to end the proceedings before morphing into a single chanted word, Justice, seeking redress for the dead and bereaved. Both of these examples illustrate the emotional intensity played out in moving acts of communion in football contexts; revealing positive features of football fandom, its capacity for venting and holding strong emotions, and potential for solidarity amongst peers. YNWA has become a recognised anthem deployed and appreciated by football fans the world over, expressing such camaraderie and unity.

What has this got to do with nursing and mental health services? In this paper we use our evaluation of a football and mental health project to explore participants' experiences of supportive group social relations. We apply the lyrics of YNWA to frame our analysis because they capture some of the key themes we wish to highlight - the importance of solidarity, peer support and alliances in overcoming adversity. We also stress the role of selfdisclosure in participants' accounts, as an important foundation for the evident mutuality and solidarity. Using these lyrics also involves deploying metaphor to help make sense of an 
initiative that itself exploits the therapeutic potential of metaphor (Jones 2009; Spandler et al. 2013b).

\section{It's a Goal!}

Footballing mental health care initiatives, both playing and spectating, have shown various positive well-being outcomes (Barraclough 2002; Carter-Morris 2001; Danforth 2003; Hynes 2008; O'Kane \& McKenna 2002; Oldknow \& Grant 2008; Pringle 2009). The It's a Goal! (IAG) programme makes use of football metaphor, grounded in cognitive-behavioural techniques, to engage, primarily, male participants in a therapeutic programme (Jones 2009; Pringle \& Sayers, 2006). It was developed by a community psychiatric nurse who became increasingly frustrated with the constraints of mental health services and the nursing profession. For example, misgivings that clinical language and settings did not helpfully engage people, especially men (see Sayers \& Spandler 2015). The programme supports individuals to achieve personal goals and takes place in small groups for eleven weekly sessions, lasting roughly two hours, typically meeting in rooms within local football stadia. The initiative is independent of mainstream mental health services but takes referrals from general practitioners, secondary care, job centres, or people can self-refer. Football becomes a 'hook' to draw people in, tapping into the ubiquity of sport in contemporary society and effectively opening up a discursive therapeutic space that hitherto might have been off-limits for men reluctant to voluntarily access mental health services (Spandler et al. 2013; Spandler et al. 2013a).

In line with the football metaphor, the group facilitators are referred to as 'coaches' and the participants as 'players'. Coaches are encouraged to wear casual, even sporty clothes to emphasise this framing, and to minimise associations with health professionals. As well as sharing things like football-team allegiances, the IAG coaches are encouraged to draw on their own life experience (e.g. mental distress, unemployment, or relationship breakdown) using appropriate self-disclosure in supporting players. The coaches are not necessarily trained mental health professionals and they are not employed specifically as peer support workers, but for the purposes of the programme they deliberately and productively blur distinctions between themselves and 'players' by emphasising commonality of experience 
Similarly, the group encourages player-to-player self-disclosure resulting in mutually supportive dialogue between peers and with the coach. As such, the study is well placed to explore experiences and understandings of group social relations, therapeutic alliance and associated self-disclosure in a mental health context.

The overall evaluation found that participants experienced a variety of mental health benefits (Spandler et al. 2013) confirming findings from previous evaluations of IAG (Pringle \& Sayers 2004; Pringle \& Sayers 2006; Smith \& Pringle 2010). Elsewhere we outline the effectiveness of the programme as a whole (Spandler et al. 2013a); therapeutic value of football metaphor (Spandler et al. 2013b); and gender relations within the programme (Spandler et al. 2013a; Spandler et al. 2014).

\section{Methods}

We undertook a mixed methods evaluation of IAG located in seven professional football clubs in the North West of England. Ethical approval was secured from our university's research governance and ethics committee. We facilitated six focus groups with players who had completed the programme (40 participants in total) and one with the coaches (6 participants). The majority of individuals accessing IAG were working class, white men, often unemployed and experiencing such difficulties as anxiety, depression, anger, low selfesteem, or difficulties related to drug and alcohol use. The focus groups were organised using a semi-structured schedule exploring participants' experiences of the IAG approach and use of football metaphor, how these compared to experiences of other mental health services, and possible ideas for improving IAG. Focus groups were audio-recorded and transcribed.

The qualitative data was subject to thematic analysis (Coffey \& Atkinson 1996) to illustrate and explore ways in which participating 'players' and 'coaches' discussed aspects of the programme they found particularly beneficial. All three researchers undertook analysis and agreed the identified themes in a continual dialogue. Commencing with open-coding, analysis proceeded manually, via cyclical reading and re-reading of the transcribed data. Relationships formed between players (peer-to-peer) as well as with coaches were seen as vital elements of 
the therapeutic benefits accruing from the programme. Therefore, this paper specifically identifies and reflects upon the supportive social relations within the programme. We go on to discuss these findings in the context of literature dealing with issues of self-disclosure, boundaries and therapeutic alliance in mental health services. We conclude by reviewing the benefits of programmes like IAG as complementary or alternative approaches to mainstream practices, also considering wider lessons for mental health practitioners.

Our analysis identified three key themes: reciprocity and mutual support; cultivation of positive emotions and identity; and a specific contrast with experiences in psychiatric services. We describe each of these themes in turn, illustrating them with anonymised quotes from participants (in all cases from players). Selected lyrics from YNWA are used to title these themes; illustrate the content; and mirror the use of football talk in the programme.

\section{'You'll never walk alone': reciprocity and mutual support}

In line with the football metaphor, a sense of being a team was deliberately fostered in the programme and was appreciated by participants who almost universally reported positive views of the extent and quality of connections between peers and between the group and their coach:

The big thing was becoming a team and rooting for each other, helping each other out... We have become a team ourselves and are bouncing off each other and supporting each other, like if one player isn't doing so well we can support them.

Solidarity also extended to putting aside differences. For example, before starting the group, one person with a background of problematic drug use described how he had anticipated there would be tensions between drug users and those with mental health issues in the programme but was pleased to find these had not materialised: 
Everyone in the group was different and that was good, people from all walks of life, it helps to break down barriers.

Processes of mutuality and reciprocity that developed within the group were deemed influential in sustaining positive outcomes, and shared experience was valued:

No-one understands unless they've been there ... We are like each other's doctors here.

The programme created a space in which differences could be contained, people could have a shared experience of mutual vulnerability and see the similarities in different struggles (Anderson 1981). This was a space in which people could think together; a fluid collective process involving generating ideas, trying them out and reflecting on them:

It's not only about shared experience .. you like grow, its like a big family really.. you can think of techniques as a group. You can think, that sounds good, I might try that. If it works for me, you learn off other people.

The players also drew on the life experiences of the coaches as a resource, with a degree of shared experience of the sort of mental health needs that had brought people into the group in the first place. Ultimately, this added to appreciation of the programme and perceptions that coaches were credible, acceptable and sincere about supporting players with their problems:

You have got the different experiences of the people running it ... its not so much about getting completely over it but more learning to dance with it, know where you are, take it a bit at a time. Certainly having people who have experienced it [mental distress] running it is a great benefit. It does offer credibility to them.. they are much better able to adapt, to understand ... where you are. 
The sense of togetherness the programme fostered was a counter to previous experiences of dislocation and loneliness. Participants gained strength from hearing of other people's ways of making sense of mental distress and approaches to coping:

You can be quite isolated I think with things like depression and so on. You start to kind of withdraw from society really .. it builds your confidence just being with other people but its more than that .. it is that experience of saying "you're not the only one”, somehow it doesn't matter how it is you got to where you are, there are other people like you, other people who understand it. A lot of people don't understand mental health. You're always going to have people who say "just get over it".

Players spoke both about the way in which they gained their own benefits from IAG but also felt they were helping each other; processes of agency and vicarious agency. People swapped phone numbers and texted each other and reported still keeping in touch after the course finished. Positive advantages of peer mutuality and reciprocity meant givers of support also accrued benefits. Players' genuine concern for each other's' welfare and shared sense of achievement in each other's success coincided with concern for the overall success of the initiative:

We got through it all, we helped each other, we done really well.

I felt a real responsibility towards it, like I didn't want anyone to mess it up for everyone else.

Shared recognition amongst group members, including, and perhaps especially, on the part of the coaches, was at least in part facilitated by a degree of flexibility in interpersonal boundaries resulting in moments of self-disclosure by participants: 
[the coach] got involved, talked about his problems of the past, problems now, you know. And you think to yourself, he's gone through that, he's done that, you know?

He was on a level with us... He spoke on a level and shared his own life experience.

A sense of common ground between group members and group facilitator would minimise anxieties about taking part:

You are automatically put on ease because you know you are not going to have to explain yourself.

This identification with each other as having had similar experiences was noted with reference to other care and treatment contexts were one might also come across workers who have previously experienced similar problems, or where disclosure of one's own problematic life experiences is encouraged amongst peers and relevant to the support offered:

It's like when you go in rehab. The majority of the people in rehab are alcoholics, recovering alcoholics, so it's the same kind of thing.

The coaches seemed to have achieved an important balance between appropriate selfdisclosure and retaining a focus on the player's needs: 
He strikes the right balance between sharing stuff about himself and making it about us.

You realise everyone is human, and he's running the course and he's telling us a bit about his life and it allows us to bond more as in open up more and project ourselves...As we were letting a bit of ourselves out, he was letting a bit of himself out and you could relate to him better than to a doctor or a nurse in hospital.

Beyond the football metaphor in terms of people's interest in and participation in actual football, the isolation of mental distress had had a negative impact on people's lives. Many service users were unemployed and materially disadvantaged and over time had lost interest in attending football games not possessing enough money for tickets. This could be a vicious circle, resulting in even more isolation as they lost touch with friends. The IAG project often helped people to reignite their interest in football - and they often did this together. For example, some started playing football together, some went to matches, and one bought a season ticket for his home-town club. More often it was simply by exchanging text messages, ostensibly about football related results and news (between players and sometimes from coaches to players), however these were often a means to stay connected and these small points of contact were valued by a group of people who had felt so disconnected before the programme.

As evoked in the song YNWA, the players were truly not 'walking alone'; solidarity in the group was felt to be pivotal for both positive experiences and outcomes. A key foundation for this was a sense of inter-personal connection, framed by the programme, the setting and to some extent precipitated by self-disclosure within the group.

\section{‘Hold your head up high’: Instilling hope and pride}


Some of the explicit content of the programme sessions, together with individuals' own goal setting, which was a significant part of the process, combined to promote confidence and assertiveness amongst participants. Exemplar players from successful football teams would be referred to in this regard. For example, coaches might refer to 'the Steven Gerrard walk' as a model for how to hold yourself on the pitch (and in life), command respect and project confidence and authority:

The attributes of different players, strikers having confidence, midfielders needing to hold things together and all that ...provided a good way of looking at my own issues

It certainly helps when you look at the different players and the different positions and then you relate those characteristics to your own life.

At the time Gerrard was club captain for Liverpool and international captain of the England team. Incidentally, his leadership was celebrated as crucial to the great Istanbul comeback referred to in the introduction. Such examples would be discussed in the group, with lessons picked up for both individuals and the group.

Becoming more hopeful about the future and taking pride in personal and collective successes was also part of the players' experiences:

I definitely feel more confident now. I feel like I can go out without fear.

At the end I felt my head was held high.

This was similarly linked to goal setting, reporting back achievements, and group solidarity. A consistent feature of the sessions was players responding positively to each other's efforts towards personal goals. In line with the football metaphor, the groups would recognise top 'goal scorers' and players of the week. In such ways confidence, pride and esteem would be 
boosted. This is important because it suggests that the structure of the programme allowed people to help each other, explicitly demonstrating acts of solidarity and togetherness. Football provides a basis for these interactions, in the context of the game itself and the interactions within the programme. As reflected in the lyrics of YNWA and the behaviour of famous football players, the participants could begin to hold their heads high.

\section{'When you walk through a storm': Contrast with psychiatric services}

Many of the participants recalled negative experiences of mainstream services leading them to make comparisons with the IAG programme. As we have seen, these distinctions reflected the strong peer support elements and flexible boundaries evident in the IAG approach. Many felt that the programme resulted in positive benefits and outcomes that were largely unrealised in standard psychiatric settings. Participants invariably drew out the differences between the coaches, whom they had much affinity for, and less valued personnel from the various mental health services' professional ranks. A key part of these divergences was that the mainstream dealt in medical/psychiatric ideas and methods, and IAG coaches did not:

It's not as much textbook. Its ... you know, you see psychiatrists .. he tells you this, you tells him that, and he puts you on medication, whichever medication he thinks is suitable, its all by the book. Like I told the psychologist this morning, you all seem to play it by the book. This was totally different.

Similarly, the more flexible boundaries within IAG were contrasted with those exhibited in standard care settings:

I know things about my coach [name] I don't treat [name] as my coach I treat him as my mate now. We have become friends. We text each other. I'll text him about football, he'll text me, you know things like that ... you'd probably never meet your psychiatrist for a brew, would you? .. They probably haven't got the time, 
psychiatrists and psychologists have they? Even after keeping you waiting for a couple of hours. Anyway they'd be testing you over a brew, its different.

The experiences of mainstream mental health care were not unremittingly devalued, but positive attributes of valued practitioners were similar to characteristics exemplified in the IAG coaches' contribution to interpersonal relations. In particular the more permeable boundaries operated by IAG coaches, which included informal contact (e.g. by text) across the week were especially valued by men who were often extremely isolated before the programme. These human qualities were, again, unlikely to be framed by medical or technical expertise:

Don't get me wrong, I'm not trying to criticise health professionals but I have had a few therapists who were not any good. In the same breath I've had many who were absolutely fantastic. The good ones tend to, you feel like they care. You know what I mean, they are much better able to engage with you and kind of understand and adapt and be sort of political I suppose, you can imagine them being good debaters. Whereas some of them, they don't seem to have that, they have a very fixed, rigid way of doing it.

Also emerging in the above quote is dissatisfaction and frustration with inflexible, monolithic, bureaucratic services; a point taken up by other participants:

One big issue I've found with the NHS is you go from one element of it to another and you have to explain yourself to every single one of them. And they take reams and reams of notes. What the hell is the problem with reading these damn things? 
The YNWA lyrics use a weather metaphor for life's trials and tribulations. In this theme 'walking through a storm' suggests the emotional turbulence of mental distress and difficult life experiences, but also the often unsatisfying experiences of participants within mainstream services.

\section{Discussion: Mental health services, therapeutic alliance, self-disclosure and boundaries}

The notion of 'therapeutic alliance' is prominent in consideration of mental health care and progressive thinking in mental health nursing (Barker 1998; Hewitt \& Coffey 2005; O’Brien 2001; Peplau 1952). Amid recent policy impetus for 'recovery oriented' care, compassionate relationships are seen as pivotal to instil the hope that would render recovery meaningful (Spandler \& Stickley 2011; Stanhope et al. 2013). In counselling and psychotherapy, the quality of 'therapeutic alliance', experienced by service users, regardless of type of psychotherapeutic approach, is seen as an important feature of the therapy process and is consistently associated with positive outcomes (Baldwin et al. 2007; Frank \& Frank 1991; Horvath \& Symonds 1991; Hubble et al. 1999; Lambert 1992; Martin et al. 2000; Muran \& Barber 2010). Indeed, Johansson \& Eklund (2003) found that the 'helping alliance' was most commonly perceived by service users as influencing good care, and suggest that attention to the quality of relationships ought to be more prominent features of general psychiatric services.

Nurses' and other mental health practitioners' capacity to establish therapeutic relations can exist in tension with their role in mediating, managing and controlling aspects of mental health care (Morrison 1990; Porter 1993). However, this need not preclude therapeutic alliance altogether (Cleary 2003). This mixed picture reflects the narratives of the IAG players, who, whilst not universally critical of all mainstream practitioners, nevertheless were mostly dissatisfied with a perceived lack of alliance in their experiences of standard care. This would typically be contrasted with the more friendly, open, informal and therapeutic relationships available in the football project. The influence of alternative, non-clinical 
settings and language is influential in this regard (Spandler et al. 2013; Spandler et al. 2013b), but an equally important foundation is efforts to build alliances and solidarity between peers.

Arguably, the likelihood of seeking out psychological services to some extent depends upon an individual's willingness to engage in self-disclosure or accept that discussion of sensitive personal information can lead to benefit (Vogel \& Wester 2003). Use of self-disclosure on the part of the therapist can encourage individuals to anticipate that care will be forthcoming (Goldstein 1994). Hence, a degree of reciprocity is at stake in acts of self-disclosure. Regardless of who is disclosing, professional or peer, people are more likely to reveal interpersonal information of their own in response to self-disclosure on the part of others, and to be interested in their lives or express positive feelings towards them (Collins \& Miller 1994; Kleinke 1979).

Whilst nurses are rarely explicitly trained not to self-disclose, it tends to be treated with sensitivity and caution. The extent to which self-disclosure is practised by mental health practitioners is limited, and might not typically include references to personal distress and vulnerability (Hill \& Knox 2001). Conti-O'Hare (2002: 2) suggests that professionals such as nurses might be disinclined to reveal themselves because of anxieties about vulnerability in the face of increasing work pressures, demands and expectations. This contrast is often seen most acutely in inpatient wards, which are increasingly organised around compulsion, coercion and risk management. Here there may be even less inclination towards such selfdisclosure, or in some cases a tendency towards prohibition. Aversion to self-disclose can be rationalised in contemplation of flagrant boundary violations, but neither self-disclosure nor a degree of boundary flexibility need necessarily lead to such malpractice (Dulit et al. 2001).

A number of mental health professionals, however, have also experienced significant mental health problems (Holbrook 2000). The idea of a 'wounded healer' being well placed to offer appropriate support grounded in personal experience has long been recognised (Barker et al. 1998; Conti-O'Hare 2002; Wolgien \& Coady 1997). In one notable example, Mary O’Hagan 
(2014) in a memoir of her own madness and treatment in mental health services tellingly highlights the positive impact of a practitioner prepared to disclose his own vulnerabilities, compared to various less helpful relationships with more distant and seemingly uncaring staff.

Social relations in care contexts also involve peer relationships, and contemporary services have begun to harness some of the value of peer support (Bouchard et al. 2010). The employment of peer support workers usually leads to improved outcomes or is at least no worse than treatment as usual (Repper \& Carter 2011; Simpson et al. 2014). Service users and the peer workers themselves experience a sense of increased empowerment or independence, self-esteem and confidence. There is some evidence that service users improve social functioning, repair denuded social networks and renegotiate a more positive identity. Arguably, the active ingredients of this helping process include recognition of shared experiences, leading to mutually agreed actions or coping. There may also be an implicit or explicit turn away from illness models towards more negotiated individual support (Mead et al. 2001; Mead \& MacNeil 2006; Repper \& Carter 2011; Solomon 2004). By implication, discussions of shared experience amongst peers must involve a degree of self-disclosure.

Mutual support has been extensively used to support people with drug and alcohol problems to develop new social networks (Kelly et al. 2011). More recently the adoption of the language of 'recovery' into substance misuse policy has resulted in an increased focus on peer support in treatment programmes, being a longstanding cornerstone of AA approaches (Roy 2014). This has involved purposive appointment of staff who have survived such problems as co-workers and the encouragement of quasi-confessional disclosure as a key element of certain treatment approaches. Similarly, it is not unknown that some staff within eating disorder services have attempted to make use of shared personal experiences in the act of helping clients (Johnson 2000; McGilley 2000). To some extent, the recent momentum to capitalise on peer support in general mental health services has been grounded in attempting to learn lessons from more avant-garde services and also the fairly obvious observation that informal peer support occurs spontaneously throughout the psychiatric system and external to it (Mead \& MacNeil 2006). Indeed patients often report that the most important therapeutic 
relationships they developed in hospital were actually with other patients and this knowledge was one of the reasons behind the development of 'therapeutic community' styles of organising psychiatric services, with peer support purposively part of 'treatment' (Kennard 2004; Spandler 2006; Winship 2004). This was definitely the case for IAG, where peer support and the structure of the programme enabled participants to begin to 'hold their heads high'.

Peer support-type programmes are not immune from criticism in a context of organisational constraints. For example, the established workforce can fear threats of role substitution with lower paid workers and cheaper services (Simpson 2013). Within the new policy landscape framed by austerity, uncertainty and shrinking budgets, any investment in peer support, risks the possibility that staff may interpret it as a competition for diminishing resources. This can make solidarity and partnership difficult to achieve in a context of all too real fears about job security (Bauman 2000; Randall \& McKeown 2014). Also, employment of peer support workers within the psychiatric system can risk de-radicalising the user movement, diverting it away from campaigning. Repper and Carter (2011: 400) are also concerned with 'where the boundaries in peer support workers relationships belong', perhaps further demonstrating that professional concerns about inter-personal boundaries exist in some tension with the contemporary value afforded to peer contributions to care.

\section{Conclusions: 'at the end of the storm there's a golden sky'}

Taken together, the relative success of peer support workers in general psychiatric services, evidence from other specialist areas such as drug rehabilitation, appreciative service user narratives, and the findings of this study suggest that more could be made of peer-to-peer support across mental health care. In more transformative terms, the mix of mutual support demonstrated in the IAG initiative, is supportive of growing interest in the value of more relational and collectivised models of care such as therapeutic communities, Soteria, or Open Dialogue as alternatives to established models of care (Calton et al. 2008; Calton \& Spandler 2009). 
The pivotal role of self-disclosure in projecting a warm, friendly and therapeutic identity on the part of the coaches in this study suggests it is time to revisit such practices within general care settings. Notably in inpatient settings, a degree of emotional distance between staff and service users is reported; undoubtedly compounded by increasing levels of compulsion and coercion (Newton-Howes 2010). In addition, there can be a spatial demarcation on psychiatric wards, with nursing staff spending lengthy periods away from face to face interaction with patients, attending to administrative tasks. Whilst the answers to some of this are to be found in efforts to reorganise nurses' work to enable more meaningful contact with service users, a question remains regarding how best to establish therapeutic alliances.

We contend that mental health nurses can learn from coaches in our study and become less reluctant to purposively disclose common experiences, shared interests and the sort of personal stories that help to establish a human connection. This is not an exhortation to be cavalier about boundaries or to neglect the needs of distressed individuals by inappropriately turning the conversation to discussion of one's own worries and problems. Rather, it is an acknowledgement that we all share a vulnerability to mental distress, and helping relationships are not served by pretending otherwise. Furthermore, we should acknowledge that if we are committed to democratisation of care relations, then disclosure ought to be reciprocal; a one-way street is simply unfair and likely to be counter-productive.

Whilst the coaches are not fully fledged peer support workers, they do engage in mutual selfdisclosure and some degree of shared identification, and such reciprocity establishes stronger relationships within the groups. This opens the door to discussion of coping strategies, realisation of personal goals, and sustains well-being. Football metaphor captures initial interest and fosters solidarity and togetherness. YNWA symbolises the triumph of solidarity over personal adversity, this spirit is embodied in initiatives such as IAG and has the potential to be more fully integrated into routine mental health care. 
Acknowledgments: The study was funded by the North West Mental Health Improvement Programme. It's a Goal! was devised and developed by the It's a Goal! Foundation www.itsagoal.org.uk/ It is now hosted by the social enterprise Unlimited Potential. In the spirit of the programme we would like to declare our own football fan affiliations: MM and AR are both supporters of Liverpool Football Club, whilst HS supports Norwich City Football Club. 


\section{References}

Anderson, D. (1981). Perspectives on treatment - the Minnesota experience. Minnesota: Hazelden Foundation.

Balague, G. (2005). A season on the brink. A portrait of Rafael Benitez's Liverpool. London: Weidenfeld \& Nicolson.

Baldwin, S., Wampold, B. \& Imel, Z. (2007). Untangling the alliance-outcome correlation: Exploring the relative importance of therapist and patient variability in the alliance. Journal of Consulting and Clinical Psychology, 75 (6), 842-852.

Barker P. (1998). Sharpening the focus of mental health nursing: primary health care. Mental Health Practice, 1(7), 14-15.

Barker P., Jackson S. \& Stevenson C. (1999). What are psychiatric nurses needed for? Developing a theory of essential nursing practice. Journal of Psychiatric and Mental Health Nursing 6, 273-282.

Barker, P., Manos, E., Novak, V. \& Reynolds, B. (1998). The wounded healer and the myth of mental well-being: Ethical issues concerning the mental health status of psychiatric nurses. In Barker, P. \& Davidson, B. Psychiatric nursing: ethical strife (pp. 334-348). London: Hodder Arnold.

Barraclough, C. (2002). Getting your head to the ball. Mental Health Nursing, 22 (5), 10-1.

Bauman, Z. (2000). Am I my brother's keeper? European Journal of Social Work, 3 (1): 511. 
Bouchard, L., Montreuil, M. \& Gros, C. (2010). Peer support among inpatients in an adult mental health setting. Issues in Mental Health Nursing, 31 (9), 589-598.

Carter-Morris, P. \& Faulkner G. (2003). A football project for service users: the role of football in reducing social exclusion. Journal of Mental Health Promotion, 2 (1), 24-30.

Calton, T., Ferriter, M., Huband, N. \& Spandler, H. (2008). A Systematic Review of the Soteria Paradigm for the Treatment of People Diagnosed with Schizophrenia. Schizophrenia Bulletin 34, 181-192.

Calton, T. \& Spandler, H. (2009). Minimal-medication approaches to treating schizophrenia. Advances in Psychiatric Treatment, 15 (3) 209-17.

Cleary, M. (2003). The challenges of mental health care reform for contemporary mental health nursing practice: Relationships, power and control. International Journal of Mental Health Nursing, 12, 139-147.

Coffey, A. \& Atkinson, P. (1996). Making sense of qualitative data. Thousand Oaks, CA: Sage.

Collins, N. \& Miller, L. (1994). Self-disclosure and liking: a meta-analytic review. Psychological Bulletin, 116, 457-475.

Conti-O'Hare, M. (2002). The nurse as wounded healer: From trauma to transcendence. Sudbury, MA: Jones \& Bartlett Learning. 
Danforth, J. (2003). Football for fun. A Life in the Day 7 (1), 25-28.

Dulit, R., Goldman, B., Siris, S., Sonis, W., Bank, P., Hermann, R., \& Fornari, V. (2001). Reexamination of therapist self-disclosure. Psychiatric Services, 52 (11), 1489-1493.

Frank, J. D. \& Frank, J. B. (1991). Persuasion and healing: A comparative study of psychotherapy (3rd ed.). Baltimore: Johns Hopkins.

Goldstein, E. (1994). Self-disclosure in treatment: what therapists do and don't talk about. Clinical Social Work Journal, 22, 417-433.

Hewitt, J. \& Coffey, M. (2005). Therapeutic working relationships with people with schizophrenia: literature review. Journal of Advanced Nursing, 52, 561-570.

Hill, C. \& Knox, S. (2001). Self-disclosure. Psychotherapy: Theory, Research, Practice, Training, 38, 4, 413-417.

Holbrook, T. (2000). The experiential connection. Perspectives: A Professional Journal of the Renfrew Center Foundation, 5 (2), 10-11.

Horvath, A. \& Symonds, B. (1991). Relation between working alliance and outcome in psychotherapy: a meta-analysis. Journal of Consulting and Clinical Psychology, 38(2), 139149.

Hubble, M., Duncan, B. \& Miller, S. (Eds.) (1999). The heart and soul of change: what works in therapy. Washington, DC: American Psychological Association. 
Hynes, J. (2008). The Positive Mental Attitude (PMA) Football League. A Life in the Day, 12 (3), 6-10.

Johansson, H. \& Eklund, M. (2003). Patient's opinions on what constitutes good psychiatric care. Scandinavian Journal of Caring Science, 17, 339-346.

Johnson, C. (2000). Been there, done that: the use of clinicians with personal recovery in the treatment of eating disorders. Perspectives: A Professional Journal of the Renfrew Center Foundation, 5 (2), 1-4.

Jones, A. (2009). Football as a metaphor: learning to cope with life, manage emotional illness and maintain health through to recovery Journal of Psychiatric and Mental Health Nursing, 15 (5), 488-492.

Kelly, J.F., Stout, R.L., Magill, M., and Tonigan, J.S. (2011). The role of Alcoholics Anonymous in mobilizing adaptive social network changes: a prospective lagged mediational analysis. Drug Alcohol Dependence, 114, 119-126.

Kennard, D. (2004). The therapeutic community as an adaptable treatment modality across different settings. Psychiatric Quarterly, 75 (3), 295-307.

Kleinke, C. (1979). Effects of personal evaluations. In G. Chelune (Ed.) Self-disclosure: origins, patterns, and implications of openness in interpersonal relationships (pp. 59-79). San Francisco, Jossey-Bass.

Lambert, M. (1992). Implications of outcome research for psychotherapy integration. In J. Norcross \& M. Goldfried (Eds.), Handbook of psychotherapy integration (pp. 94-129). New York: Basic Books. 
Martin, D., Garske, J. \& Davis, M. (2000). Relation of the therapeutic alliance with outcome and other variables: a meta-analytic review. Journal of Consulting and Clinical Psychology, $68,3,438-450$.

McGilley, B. (2000). On the being and telling of the experience of anorexia: A therapist's perspective. Perspectives: A Professional Journal of the Renfrew Center Foundation, 5 (2), $5-7$.

Mead, S., Hilton, D., \& Curtis, L. (2001). Peer support: a theoretical perspective. Psychiatric Rehabilitation Journal, 25 (2), 134-141.

Mead, S. \& MacNeil, C. (2006). Peer support: What makes it unique? International Journal of Psychosocial Rehabilitation, 10, 2, 29-37.

Morrison, E. (1990). The Tradition of Toughness: A Study of Nonprofessional Nursing Care in Psychiatric Settings. Image: the Journal of Nursing Scholarship, 22, 1, 32-38.

Muran, J. \& Barber, J. (eds) (2010). The therapeutic alliance: an evidence-based guide to practice. New York: Guilford Press.

Newton-Howes, G. (2010). Coercion in psychiatric care: where are we now, what do we know, where do we go? Psychiatric Bulletin, 34, 217-220.

O’Brien A. (2001). The therapeutic relationship: historical development and contemporary significance. Journal of Psychiatric and Mental Health Nursing, 8, 129-137. 
O’Hagan, M. (2014). Madness made me. A memoir. Wellington, NZ: Open Box.

O'Kane P. \& McKenna B. (2002). Five a side makes a difference. Mental Health Nursing, $22,8-12$.

Oldknow, H. \& Grant, G. (2008). Does joining a football academy help mental health recovery? Mental Health Nursing, 28, 2, 8-11.

Peplau H. (1952). Interpersonal relations in nursing. New York: G. P. Putnam \& Sons.

Porter, S. (1993). The determinants of psychiatric nursing practice: a comparison of sociological perspectives. Journal of Advanced Nursing, 18, 1559-1566.

Pringle, A. (2009). The growing role of football as a vehicle for interventions in mental health care. Journal of Psychiatric and Mental Health Nursing, 16, 553-557.

Pringle, A. \& Sayers, P. (2004). It's a goal! Basing a CPN service in a football stadium. Journal of the Royal Society for the Promotion of Health, 124 (4), 234-238.

Pringle A. \& Sayers P. (2006). It's a Goal! the half time score. Mental Health Nursing, 26 (3), 14-17.

Randall, D. \& McKeown, M. (2014). Editorial. Failure to care: nursing in a state of liquid modernity? Journal of Clinical Nursing, 23, 766-767. 
Repper, J. \& Carter, T. (2011). A review of the literature on peer support in mental health services. Journal of Mental Health, 20, 392-411.

Roy, A. (2014). Looking beneath the surface of recovery: Analysing the emergence of recovery oriented treatment policies, in D. Korf, T. Decorte \& G. Potter (eds) Drugs in Europe: change and continuity. Pabst: Lengerich.

Sayers, P. and Spandler, H. (2015). 'It's a Goal: a football-based mental health programme' in D. Conrad and A. White Sports-Based Health Interventions: Case Studies from Around the World. Berlin: Springer Press.

Simpson, A. (2013). Peer support in mental health needs a welcome, not wariness. Nursing Times, 109 (26), 7.

Simpson, A., Flood, C., Rowe, J., Quigley, J., Henry, S., Hall, C., Evans, R., Sherman, P. \& Bowers, L. (2014). Results of a pilot randomised controlled trial to measure the clinical and cost effectiveness of peer support in increasing hope and quality of life in mental health patients discharged from hospital in the UK. BMC Psychiatry, 14 (1), 30.

Smith, M., \& Pringle, A. (2010). The latest score: an evaluation of the It's a Goal! programme. Nottingham: SAMHS and the University of Nottingham.

Solomon, P. (2004). Peer support/peer provided services underlying processes, benefits, and critical ingredients. Psychiatric Rehabilitation Journal, 27 (4), 392. 
Spandler, H. \& McKeown, M., Roy, A. \& Hurley, M. (2013). Football metaphor and mental well-being: An evaluation of the It's a Goal! programme. Journal of Mental Health, 22, (6), 544-554.

Spandler, H., Roy, A \& Mckeown, M. (2013a). Competing for the Turf?: A gendered exploration of using football talk in a mental health project. In D. Hynes \& A. Kiernan (eds) Football and its communities (pp. 95-106). Oxford: Interdisciplinary Press.

Spandler, H., Roy, A. \& McKeown, M. (2013b). The therapeutic benefits of football metaphor. Journal of Social Work Practice, 28 (2), 229-245.

Spandler, H. Roy, A. \& McKeown, M. (2014). Playing by the rules? Gender relations in a football and mental health project Journal of Men's Studies, 22 (2), 140-154.

Spandler, H. \& Stickley, T. (2011). No hope without compassion: the importance of compassion in recovery-focused mental health services. Journal of Mental Health, 20, 555566.

Stanhope, V., Barrenger, S., Salzer, M. \& Marcus, S. (2013). Examining the relationship between choice, therapeutic alliance and outcomes in mental health services. Journal of Personalized Medicine, 3, 191-202.

Vogel, D. \& Wester, S. (2003). To seek help or not to seek help: the risks of self disclosure. Journal of Counselling Psychology, 50, 351-361.

Winship, G. (2004). Democracy in practice in 14 UK psychotherapeutic communities. Therapeutic Communities, 25 (4), 275-290. 
Wolgien, C. \& Coady, N. (1997). Good therapists' beliefs about the development of their helping ability: the wounded healer paradigm revisited. The Clinical Supervisor, 15, (2), 1935. 